\title{
Precarizaciones salariales y resistencias sociales: ¿Hacia una renovación de la mirada sociológica desde el caso francés?
}

\author{
Sophie BEROUD \\ Université Lumière Lyon 2, Triangle (UMR 5206) \\ sophie.beroud@univ-lyon2.fr \\ Paul BOUFFARTIGUE \\ Aix-Marseille Université, CNRS, Lest (UMR 7317) \\ bouffartig@univmed.fr
}

Recibido: 27-04-2013

Aceptado:11-09-2013

\section{Resumen}

La precarización del mundo laboral se encuentra íntimamente ligada a su debilitamiento como actor colectivo. Pero al mismo tiempo es portadora de potencialidades de resistencia social y de reestructuración de la forma sindical. Una mejor identificación de estas últimas arroja una nueva luz sobre la historia de los asalariados y sus respuestas ante la inseguridad. En particular, parece interesante explorar las dinámicas de estabilización de los asalariados y de reivindicación de una movilidad no impuesta. Esta digresión histórica no sólo permite identificar las dimensiones auténticamente nuevas del actual proceso de precarización, sino también cuestionar la manera como las organizaciones sindicales lo enfrentan.

Palabras clave: precariedad, movilidad, sindicalismo, conflictos sociales.

\section{Precariousness and social conflict: To a renewal of the sociological perspective?}

\begin{abstract}
Increasing precariousness among workers is closely associated with trade unionism contemporary weakness. But this process also open new possibilities for social resistance and - union's form and repertoire of actions recomposition. To identify these we need to revisit wage labor history and different types of responses to reduce insecurity. It seems particularly interesting to examine the stabilization dynamic of wage and the claims for unconstrained mobility. This historically detour helps to identify the truly new dimension in the process of contemporary insecurity and question how trade unions are reacting.
\end{abstract}

Keywords: precariousness, mobility, trade unionism, social conflicts.

\section{REFERENCIA NORMALIZADA}

Béroud S. y Bouffartigue P. (2013). Precarizaciones salariales y resistencias sociales: ¿Hacia una renovación de la mirada sociológica desde el caso francés? Cuadernos de Relaciones Laborales. Vol. 31, núm. 2, p. 455-472. 
SUMARIO: Introducción. 1. ¿Quién controla la movilidad o la estabilidad? Una vieja historia. 2. La precariedad moderna divide... iy une! 3. La forma sindical a prueba. Bibliografía.

\section{Introducción}

Antes incluso de la actual crisis económica, el sector privado experimentó en Francia cierta renovación de las formas de conflictividad social, incluso dentro de algunos de los sectores más aquejados por la precariedad profesional. De la gran distribución a la comida rápida, pasando por los trabajadores indocumentados de la construcción o del sector de la hostelería/restauración, estos conflictos demuestran que el "precariado" no está condenado a la insumisión y la invisibilidad social. Sin embargo, esto no impide que hasta la fecha perdure la profunda desestabilización de la forma sindical heredada del siglo pasado. Hoy por hoy, los sindicatos franceses sólo agrupan a un $8 \%$ aproximadamente de la población activa, principalmente en las grandes empresas del sector público y del sector privado (Pernot, Pignoni, 2008). Dicho en otros términos, la inmensa mayoría de los asalariados situada al margen de los sindicatos es aquella parte que sufre las formas de empleo precarias y trabaja en las pequeñas y medianas empresas -en la mayoría de los casos, empresas subcontratistas o de trabajo temporal-, es decir, que representa las fracciones más importantes del proletariado contemporáneo.

Así, el proceso de desestabilización de los trabajadores asalariados es indisociable del movimiento sindical y obrero. No sólo constituye una de sus principales fuentes y componentes, puesto que la atomización y la cada vez mayor fragilidad de la situación de los trabajadores agudizan el debilitamiento y las divisiones del sindicalismo, sino que al mismo tiempo constituye una de sus principales consecuencias: debilitado, el movimiento de los asalariados no logra contener la desestabilización de las normas salariales.

En la mayoría de los casos, la precarización del mundo laboral sigue interpretándose como un proceso ampliamente unilateral de descomposición de la norma salarial propio del periodo de crecimiento llamado "fordista", que llevaría consigo un ineluctable debilitamiento, no sólo del movimiento sindical, sino también de las resistencias colectivas. Basándonos en una serie de investigaciones empíricas reunidas en una obra colectiva (Béroud, Bouffartigue, 2009), en el presente artículo consideramos importante discutir semejante enfoque desde una perspectiva más global, con el objeto de pensar este proceso de precarización en su dimensión contradictoria, es decir, dialéctica. Sin negar los efectos nefastos de la precarización del trabajo asalariado, nos interesaremos en las resistencias sociales que ésta suscita, así como en las fuentes, tanto antiguas como contemporáneas, que las alimentan. Contrariamente a lo que sostiene un punto de vista ampliamente difundido, defenderemos aquí la idea de que el poderío de este proceso de precarización del mundo laboral no significa ni su inevitabilidad, ni la de una marginación definitiva del sindicalismo. Si bien la extensión y masificación de la inseguridad social generan una mayor fragilidad, división y atomización de los trabajadores asalariados, tam- 
bién propician la renovación de las modalidades y de los objetivos de la acción colectiva y abren potencialidades, tanto de reestructuración de las solidaridades como de redefinición de la base misma de la condición salarial.

El desplazamiento de la mirada sociológica supone, en primera instancia, que la secuencia actual se sitúe de manera más adecuada dentro de la historia a largo plazo de los trabajadores asalariados y de sus modos de insubordinación. De ahí la necesidad de reexaminar la referencia a los "treinta años gloriosos" que marcaron a una parte de las economías occidentales, ante la amplia mitificación de la que ha sido objeto este periodo. Si bien la norma fordista de empleo constituía el referente esencial e impulsaba una dinámica de estabilización salarial más amplia, al mismo tiempo contribuyó a ocultar la persistencia de grupos que habían permanecido al margen de este progreso social (1). En segundo lugar, este desplazamiento supone precisar la noción de precariedad y examinar lo realmente novedoso de sus formas contemporáneas. En la medida en que la incertidumbre salarial tiende a convertirse en una nueva norma, permite enunciar y denunciar los elementos comunes de una condición salarial, por lo demás profundamente diferenciada (2). Finalmente, esta renovación de la mirada requiere de encuestas que detecten las formas de resistencia y de lucha que implican a trabajadores precarios, y que de esta manera contribuyan a precisar las condiciones de una reestructuración del sindicalismo y la acción colectiva a favor del precariado.

\section{1. ¿Quién controla la movilidad o la estabilidad? Una vieja historia}

La precariedad divide y debilita a los trabajadores asalariados: éste es el fenómeno en el cual suele hacerse hincapié. Cierto es que colocar a los asalariados en situación de inseguridad facilita el despliegue de la arbitrariedad empresarial y jerárquica, así como de todas las formas de dominación y discriminación social. Sin embargo, la precariedad rara vez anula todas las solidaridades entre explotados, las cuales fundamentan la posibilidad de movimientos y organizaciones de tipo colectivo. La escala, más o menos amplia, en la que se despliegan estas solidaridades constituye un factor clave, debido a que las protecciones conquistadas por algunos lo mismo pueden alimentar nuevas divisiones, como servir de puntos de apoyo. En el momento en que la precariedad profesional se vuelve a masificar, ¿no es ésta susceptible de convertirse en factor de enlace dentro del mundo laboral? La historia de los trabajadores asalariados permite alimentar esta reflexión.

Considerado desde una perspectiva temporal más amplia, el periodo 1945-1975 durante el cual se afirmó la hegemonía de una norma salarial basada en la estabili-

${ }^{1}$ Conocidos también como "años dorados" o "edad de oro del capitalismo": período socioeconómico que vivieron los países occidentales desde el final de la Segunda Guerra Mundial, en 1945, hasta la crisis del petróleo de 1973-1975 [N. del T.]. 
dad, parece relativamente breve. Además, se trató de una hegemonía relativa, porque nunca eliminó la inestabilidad ni la fragilidad salarial inscritas en el corazón mismo de los viejos países industriales. Sectores enteros de actividad -agricultura, industria agroalimentaria, construcción, comercio, trabajo doméstico- siguieron marcados por la intermitencia del empleo y la mediocridad de los derechos sociales. En los grandes almacenes, por ejemplo, la libertad patronal de contratación y despido fue casi total hasta 1936, en tanto que los salarios eran a la vez bajos y homogéneos; y los posteriores progresos del derecho laboral fueron acompañados de prácticas que permitían eludirlo. Aquí, la inestabilidad de la mano de obra es una constante en la duración (Beau, 2009).

En cierta medida, este periodo de estabilización constituye la excepción que confirma la regla según la cual la precariedad es la base misma de la condición salarial. ¿Acaso no se define ésta fundamentalmente como una relación de subordinación (de una fuerza de trabajo a un empleador), a la vez que como una relación libre (ambas partes pueden ponerle fin)? La ficción de una igualdad entre las partes, propia de la ideología liberal y del derecho procedente de la Revolución Francesa, conducía a no distinguir el contrato laboral del contrato comercial y a combatir el resurgimiento de toda organización gremial. Fueron necesarios decenios de luchas obreras, combinadas con la influencia de reformadores sociales y de fracciones modernistas del empresariado, para que en el transcurso del siglo XIX emergieran los primeros rudimentos del derecho laboral. Sin embargo, a lo largo de todo este periodo no era prioritaria la reivindicación de estabilidad de la relación salarial; ésta carecía de relevancia, debido a que la seguridad de los medios de existencia pasaba ante todo por la búsqueda de recursos al margen de la relación salarial (Sauze, 2005). Los trabajadores agremiados que constituían el armazón de las primeras organizaciones obreras no reivindicaban la estabilidad, sino el derecho a la movilidad. Por ejemplo, luchaban por la supresión de la "cartilla obrera", instrumento que permitía a los empleadores retener a sus obreros en función de sus necesidades. Pero expresaban una aspiración más fundamental de los obreros a la insubordinación: ¿acaso no constituyen el derecho y la posibilidad efectiva de cambiar de patrón, la primera forma de resistencia a la explotación, cuya verdad se manifiesta a través del incremento de la movilidad voluntaria en toda coyuntura de pleno empleo o de déficit de mano de obra? Posteriormente, de un siglo a otro, todo parece haber ocurrido como si las posiciones del sindicalismo obrero y del empresariado se hubiesen invertido: hoy por hoy es el movimiento sindical el que busca oponerse a la movilidad obligada de los asalariados, tal como la reivindica el capital (Vatin y Pillon, 2003). Como se sabe, esta historia es más compleja. El binomio estabili$\mathrm{dad} /$ movilidad siempre debe cuestionarse, pues la pregunta fundamental consiste en determinar quién controla esta estabilidad/movilidad: ¿los empresarios o los trabajadores asalariados (Germe, 1981)? De la misma manera que el surgimiento, luego el desarrollo de un derecho laboral que protege a los trabajadores a cambio del reconocimiento de su subordinación (Ley sobre los accidentes de trabajo, de 1898) no debe ocultar las formas de derecho obrero que le preexistían y a través de las 
cuales una parte de los obreros calificados lograban controlar sus condiciones de trabajo (Cottereau, 2002).

Desde el siglo XIX, con el auge de la gran industria, implantada a veces lejos de las reservas de mano de obra, una parte del empresariado buscó disciplinar y fijar a una fracción de esta última. Por su parte, las manufacturas públicas instauraban cierto "patrocinio estatal" (Retière, 1995), dentro del cual se inscribiría la acción sindical, llegando en ocasiones a subvertirlo. Controlada -al menos parcialmentepor los trabajadores asalariados, la estabilidad, cuando se enmarca dentro de un estatuto protector, constituye un recurso esencial en la limitación de la arbitrariedad jerárquica. Controlada por el empresariado, la estabilidad, cuando resulta de la dominación unilateral del paternalismo, favorece la subordinación en el proceso laboral. En términos generales, si los trabajadores están sujetos en el largo plazo a la competencia y la división por parte del mercado de trabajo, lo mismo ocurre también con los empleadores. Es por ello que a estos últimos puede convenirles regular su competencia, con el fin de precaverse, en primera instancia, contra el riesgo de la falta de mano de obra. Las políticas empresariales de fijación se basan en un segundo imperativo, cuya importancia nos recuerda C. Ramaux (2006): siendo la producción irreductible al intercambio, supone una temporalidad propia que va necesariamente más allá del tiempo del intercambio, potencialmente instantáneo. Ésta es una de las bases fundamentales de los límites a los que se enfrenta, hoy como ayer, la desestabilización del empleo. Y constituye al mismo tiempo uno de los recursos esenciales de los asalariados en su resistencia a esta última.

De esta manera, los empleadores pueden ser llevados a ponerse de acuerdo entre sí dentro de un sector de actividad y/o un territorio renuente a la modalidad fabril, cuando dentro de éste se impone la necesidad de organizar la circulación de la mano de obra. Esto permite entonces imponer a esta escala los imperativos de estabilización de los asalariados. Es lo que ocurre en las actividades portuarias o de construcción, por ejemplo, cuando se constituyen mercados de trabajo "profesionales" más o menos "cerrados", en los cuales los empleadores no se encuentran, a nivel individual, en condiciones de controlar y fijar a los trabajadores. Se abre entonces un espacio extenso y original para el actor sindical: el control del mercado de trabajo, que va siempre acompañado de una intervención más o menos extensa en la organización misma del trabajo. Aquí se observa cierto control de los trabajadores asalariados sobre la movilidad, cuyas formas se oponen entonces a las que adopta la movilidad sufrida. Son los empleadores quienes sufragan colectivamente el coste ligado a los movimientos de la mano de obra. En Francia, esta práctica ha estado mucho menos desarrollada que en otros países, como el closed shop en el Reino Unido. Sin embargo, se conoce el movimiento de los obreros del Libro, de los marinos y los estibadores y, en menor medida, de los leñadores del centro de Francia, donde el control sindical de la tala, inaugurado en los años 1890, se mantendría hasta entrados los años 1950. Estas experiencias resultaron ambivalentes: por una parte estaba "la audacia de reivindicaciones que llegaban al corazón de la subordinación salarial, a la medida de las imposiciones a superar", un proceso de desprecarización y cierta difusión de los logros más allá del grupo central; por otra, los 
límites de la "interprofesionalidad como marco de identificación e intervención" (Pigenet, 2009). En el caso francés, la movilidad, cuando estaba relativamente controlada por el trabajador, adoptó con mayor frecuencia la forma del mercado de trabajo profesional abierto -el de las profesiones manuales- que la del mercado de trabajo cerrado. Pero tanto en un caso como en otro estamos muy lejos de una movilidad controlada por el empresariado, la de los obreros sin calificación contratados "por día", e incluso por lapsos de cuatro horas como ocurrió con los obreros de los muelles a quienes aún no se designaba como "estibadores".

De cierta manera la sumisión, siempre relativa, de la clase obrera a la disciplina de la Organización Científica del Trabajo sólo fue posible a cambio de cierto estatus salarial y social. Los primeros signos de esta solución de compromiso social "fordista" -que tan profunda huella dejaría en la cultura estratégica del movimiento obrero y sus impasses a lo largo del siglo XX (Trentin, 2012)- aparecen después de la Primera Guerra Mundial, en el preciso momento en que se iniciaba una doble metamorfosis del sindicalismo. La primera concernía a su arquitectura, con la afirmación de la rama de actividad industrial y, más tarde, de la empresa, a expensas del territorio local y de la profesión. La segunda concernía a su lugar y su papel como actor social: el sindicalismo, que en un principio poseía escaso arraigo y cultivaba la autonomía obrera y la exterioridad con respecto al Estado, fue adquiriendo posteriormente un importante peso social e institucional. Este movimiento de reconocimiento institucional se produjo con ciertos desfases dentro del sindicalismo francés: así, la CGT [Confédération Générale du Travail] de Léon Jouhaux inauguró esta política de presencia en el momento en que la CGU [Confédération Générale du Travail Unitaire] seguía concibiéndose a sí misma como ajena al orden social dominante. Además, para comprenderlo adecuadamente es preciso ampliar las perspectivas y tomar en consideración la dinámica de "nacionalización" del movimiento comunista francés, es decir, su aceptación del régimen y su reconocimiento como actor central de éste, alrededor de 1936.

Sin embargo, la coocurrencia de los procesos de protección de la condición salarial, de racionalización del trabajo y de reconocimiento/integración relativa del actor sindical dentro del Estado social, no debe conducirnos a relacionarlos de manera mecánica. En un país como Francia, los grandes movimientos sociales del Frente Popular y de la Liberación desempeñaron un papel lo suficientemente claro en estos avances, como para que una interpretación de estos procesos en términos de conquistas sociales sea al menos tan pertinente como la de estrategia de integración al orden social. En realidad, los dos fenómenos, íntimamente interrelacionados, deben concebirse de manera dialéctica, debido a que ejercen importantes efectos uno sobre el otro y contribuyen a que la fuerza dominante del sindicalismo en Francia -la CGT- nunca haya asumido completamente un papel de simple regulador entre el trabajo y el capital. Es verdad que esta solución de compromiso se consolidó posteriormente en la época del crecimiento fordista, durante la cual la reactivación de la acumulación del capital pasó por la ampliación del mercado de bienes de consumo masivo, y por ende del consiguiente incremento de la capacidad de gasto de una clase asalariada en plena expansión. Las corrientes ideológicas 
libertarias y/o radicales del movimiento obrero no se cansaron de denunciar esta solución de compromiso como un acomodo oportunista que incorporaba a la clase obrera a las normas de trabajo y de vida del capitalismo desarrollado. Sin embargo, esta incorporación nunca llegó a ser total, como lo demuestran no sólo las numerosas excepciones al estatus salarial moderno en el corazón mismo de las grandes empresas industriales hasta los años 1950 (Peneff, 1993; Bourguignat, 1993), sino también las numerosas manifestaciones de insubordinación obrera en los años posteriores al 68.

Incluso en los años 1960-1970 el empleo "estándar" nunca estuvo generalizado ni uniformado. Además, contribuyó a la renovación de las jerarquías dentro de la clase asalariada, y no a su supresión. Con todo, es verdad que la seguridad salarial era regla: constituía una referencia para todos y permitía a los grupos periféricos obtener ventajas salariales indirectas. Las protecciones y conquistas sociales, adquiridas inicialmente por los segmentos más combativos de la clase obrera, se difundían hacia las fracciones dominadas y menos organizadas del mundo laboral. Este movimiento se llevaba a cabo a través de una solidarización, tanto objetiva como subjetiva, de los distintos componentes de los trabajadores asalariados, dentro de cada Estado-nación. De acuerdo con una arquitectura variable según los países, las distintas escalas de la conflictividad social y la negociación colectiva -la empresa, el gremio o la profesión, la rama de actividad, el ámbito interprofesional, el Estadotendían a articularse dentro de una dinámica virtuosa de generalización de los derechos, aun cuando "los sindicalismos no buscan espontáneamente proponerse a sí mismos como agentes de difusión de los logros de sus propios miembros" (Dufour y Hege, 2009). Esta dinámica se interrumpió a finales de los años 1970. La solución de compromiso social de tipo "keynesiano-fordista" entre el capital y los trabajadores se quebrantó con la toma de poder del capital financiero dentro de la clase dirigente y el modo de globalización económica que ésta impulsa.

Como se advierte, la estabilización de los trabajadores asalariados fue un fenómeno indiscutible, aunque relativo. Resultó de una correlación de fuerzas a la vez compleja y frágil, en la que el movimiento obrero desempeñó indudablemente un papel motor, sin descuidar las necesidades propias del capital o de algunas de sus fracciones, ni las concesiones en materia de ideales de emancipación que fueron el precio a pagar. El actor salarial nunca se encuentra solo, y es en un juego de actores donde es preciso tratar de comprender sus recursos. ¿Cuáles son entonces las necesidades en materia de estabilidad o seguridad que se arraigan en las realidades productivas contemporáneas? ¿Y cuáles son las aspiraciones en materia de emancipación entre las nuevas generaciones de trabajadores?

\section{La precariedad moderna divide... iy une!}

La precariedad profesional -noción más limitada que la de precariedad social, hacia la que se han desplazado los usos sociales del término precariedad- es una combinación tendencial de las tres dimensiones de la inseguridad salarial moderna: 
el empleo (precariedad -de derecho o de hecho- del contrato laboral); el trabajo (deterioro del contenido, las condiciones y el sentido de la actividad); las relaciones profesionales y las capacidades de resistencia y de representación colectivas.

Más que la inestabilidad del empleo en sí misma -un trabajador puede tener estabilidad en una empresa y al mismo tiempo ser mantenido de facto en condiciones de empleo y trabajo deterioradas, como lo ilustra claramente la situación de los indocumentados en el sector de la restauración, por ejemplo-, aquello que constituye el elemento central de la precariedad es la inseguridad salarial en su globalidad, aun en caso de que se inscriba dentro de cierta duración de hecho de la relación de empleo. El enfoque que defendemos aquí invita a reflexionar en torno a lo que, pese a la violencia social que encierra el proceso de precarización, puede ser portador de cierto sentido en las experiencias, tanto individuales como colectivas, y por ende a no considerar este proceso exclusivamente como un factor de debilitamiento irremediable del sindicalismo. Nuestro enfoque permite establecer una íntima relación entre la calidad del estatus salarial y las modalidades de dependencia y resistencia en el trabajo. Asimismo, ayuda a poner en evidencia aquello que constituye una novedad en las formas contemporáneas de precariedad. Desde este punto de vista pueden señalarse y analizarse varios factores distintivos de capital importancia por su capacidad para producir elementos de una condición común.

1.- Dado que el proceso de asalarización de la población activa llegó a su fin, las posibilidades laborales individuales al margen del trabajo dependiente ya no son concebibles a la escala que tenían hasta la crisis económica de los años 1930. La relación salarial es más que nunca central -una dimensión que durante un tiempo pudieron ocultar los discursos en torno al fin del trabajo. No obstante, la manera como el capitalismo contemporáneo organiza, a través de la intervención estatal, nuevas categorías jurídicas que otorgan el estatus de falso trabajador "independiente" a una fracción de asalariados calificados cuya actividad es objeto de subcontratación, ilustra claramente la manera como las cosas han llegado a confundirse a partir de la figura del "auto-entrepreneur" (auto-emprendedor) ${ }^{2}$.

2.- El "retorno" de la precariedad ocurre al término de un largo periodo de construcción de una sociedad salarial y de un Estado social. Aunque no les están unidos en forma mecánica, los progresos en materia de escolarización de las clases populares o de feminización de los trabajadores asalariados son indisociables de ellos. Esto significa en primera instancia que las normas sociales asociadas a la estabilidad siguen siendo un referente fundamental y continúan alimentando los debates y conflictos en torno a la "flexibilidad". Clara prueba de ello es la magnitud de las protestas que suscitó en Francia, en 2006, el Contrat Première Embauche (CPE)

${ }^{2}$ El auto-entrepreneur (“autoemprendedor") es una figura jurídica destinada a facilitar la creación de una empresa individual; surgió en el marco de la Ley de modernización de la economía, promulgada el 4 de agosto de 2008 [N. del T.]. 
[Ley de contrato del primer empleo] que trataba de imponer un tipo de empleo específico para los menores de 26 años y preveía, entre otras cosas, una extensión del periodo de prueba. Los sábados, en particular, llegaron a manifestarse millones de personas para denunciar aquello que percibían como una ruptura del progreso social. La fuerza de estos referentes se manifiesta también a través de las recurrentes dificultades de contratación para cubrir empleos precarios, pese al desempleo masivo -empleos que a menudo se cubren recurriendo a la inmigración-. De ahí la paradoja de que los representantes de la patronal y de la derecha presentan como intolerable -la penuria de candidatos en "sectores de difícil cobertura", como la construcción-, pero que puede interpretarse de manera totalmente distinta como el obstinado rechazo a un empleo degradado por parte de amplias fracciones de las nuevas generaciones, así como la sobreexplotación de los "trabajadores asalariados reprimidos", de una "mano de obra deslocalizada en su propio país" a través de la inmigración clandestina.

Las formas contemporáneas de resistencia a la precarización profesional deben mucho a este segundo dato: incidencias del aumento de la escolarización en la negativa a aceptar una empleo de categoría menor; persistencia del apego a la movilidad voluntaria, pese a la magnitud del subempleo. Por consiguiente, la ola de desempleo y precariedad nunca ha llegado a sofocar por completo estas aspiraciones a la superación de la subordinación y, más allá de esto, a la restructuración y reapropiación personales de los tiempos sociales.

3.- Una serie de transformaciones sociales, políticas y culturales que ocurrieron desde la Segunda Guerra Mundial, alimentan las capacidades de resistencia en la esfera laboral: ampliación relativa de la democracia política -empezando por el acceso de las mujeres al sufragio universal-, impugnación de una serie de relaciones de dominación social mediante movimientos sociales que lograron desplegarse a largo plazo. Como sostiene con insistencia Isabelle Ferreras -y esta dimensión va unida a la anterior- estas experiencias de lucha, expresión de una aspiración a la emancipación individual y colectiva, tienen repercusiones en la esfera laboral que si bien está sujeta a regímenes de autoridad configurados a la antigua, tales como el régimen paternalista basado en la autoridad del empresario- no puede sustraerse completamente a los efectos de una socialización política en democracia. De ahí que la empresa no permanezca totalmente ajena a las exigencias de justicia e igualdad presentes en la sociedad, a las reivindicaciones ligadas al proceso de individualización, de reconocimiento positivo del individuo; lo cual abre, una vez más, una posible brecha -pese a la fuerza de las relaciones de dominación y alienación- en la manera de cuestionar las formas de participación en el ejercicio mismo del trabajo (Ferreras, 2007).

4.- La precarización profesional se inscribe en el marco de un fuerte retorno de la incertidumbre, que se afecta también y a su manera a la fracción mejor protegida de los trabajadores asalariados. Más aun, crea lazos objetivos de solidaridad entre los componentes relativamente estabilizados del mundo laboral y los trabajadores precarizados, en la medida en que la intensificación del trabajo y la precarización constituyen las dos caras de un mismo proceso. 
5.- Ciertas exigencias de estabilidad se fundamentan en las formas modernas de competencia profesional y de cooperación productiva. Si bien la precariedad profesional adopta principalmente la forma de una polarización de la mano de obra entre empleos precarios y empleos estables, que se traduce en el mantenimiento de una estabilidad media elevada en el empleo, este fenómeno no puede reducirse a una estabilización forzada de los trabajadores bajo el efecto de la amenaza del desempleo. El creciente papel de los servicios, el conocimiento y la implicación subjetiva en las actividades profesionales, impide generalizar el modelo del trabajador desechable.

\section{La forma sindical a prueba}

Dos premisas permiten reflexionar acerca de lo que está en juego en el proceso contemporáneo de reestructuración del sindicalismo -un proceso desigual que se está desarrollando actualmente y cuyo desenlace no se encuentra en absoluto determinado de antemano. La primera se refiere a la capacidad de los sindicatos para representar a los trabajadores asalariados en su diversidad, es decir, para promover la evolución de su propia base social; la segunda, a su eficacia para hacer frente a las transformaciones de los espacios productivos. Además, ambas dimensiones se encuentran imbricadas, como lo revelan claramente las situaciones de subcontratación que se traducen en la masificación de empleos precarios ocupados por aquellos y aquellas a quienes el sindicalismo difícilmente logra organizar.

La precarización del trabajo y del empleo tuvo por lo menos una virtud: la de poner en evidencia los límites de un tipo de sindicalismo cuya base social (un asalariado masculino, calificado, de edad madura y "blanco") distaba mucho de abarcar la totalidad de las realidades salariales. Numerosos componentes del mundo laboral eran invisibles, por estar poco -o no estar en absoluto- representados en el plano político y simbólico: las mujeres, los inmigrantes, los jóvenes. Mientras que en la época del crecimiento fordista este dato no era considerado como de vital importancia por el actor sindical, en la actualidad este último ha llegado a considerarlo como tal, debido a que el número de precarios se ha incrementado considerablemente y a que éstos tienden a estabilizarse en la precariedad. Cuando los militantes sindicales caen en la cuenta de que sus llamamientos al paro de la cadena de montaje de Renault Truck tienen un seguimiento escaso, ya no pueden pasar por alto el hecho de que la mitad de los obreros son trabajadores temporales: es entonces cuando deciden hacer frente directamente el problema y lo hacen con cierto éxito. Lo mismo sucede con los sindicalistas de La Poste ${ }^{3}$, en su mayoría con un estatus de funcionarios, que sólo empezaron a tomar en cuenta a los trabajadores temporales de Correos, incluyendo a los más precarizados, cuando vieron que a corto o medio plazo terminarían por ser mayoritarios. En este caso también llegaron

${ }^{3}$ La Poste: empresa estatal de Correos de Francia [N. del T.]. 
a obtener resultados indiscutibles en términos de estabilización de trabajadores precarios. Sin embargo, estos logros que se registraron en aquellos sectores en los cuales los asalariados gozan de cierta protección y los sindicatos conservan cierto poder, no pueden ocultar la fragilidad de los resultados de aquellas luchas, a veces tenaces, que ocurrieron en sectores basados en el precariado, tales como la gran distribución (Benquet, 2011), la comida rápida (Peroumal y Perrin, 2009), la limpieza (Denis, 2009) o la subcontratación industrial (Béroud et al., 2009).

¿Significa esto que las implicaciones fundamentales del imperativo de una reestructuración orientada hacia nuevas bases sociales han sido realmente objeto de reflexión? La distancia que separa a los trabajadores precarios del sindicalismo dista mucho de explicarse exclusivamente por las condiciones más precarias de ejercicio de los derechos sindicales; se relaciona también con una identificación social que merece calificarse, cuando menos, de problemática. "El fondo del asunto consiste en saber si el sindicalismo puede servir de lugar de identificación para un abanico más amplio de poblaciones asalariadas, a menudo en ruptura con los sistemas de alianza arraigados entre los trabajadores asalariados de mayor antigüedad" (Dufour y Hege, 2009). Los sindicatos pueden conformarse con la legitimidad institucional que les da su participación en el juego de una negociación colectiva, aunque esta última ya no guarde relación con la realidad. Por si fuera poco, la reciente reforma de las reglas de representatividad reafirma, a través de la Ley del 20 de agosto de 2008, la preeminencia de la legitimidad electoral, al mismo tiempo que ciertos sindicatos pueden obtener numerosos sufragios y ser considerados como interlocutores representativos, sin por ello hacerse cargo concretamente de los trabajadores precarios (Béroud, Le Crom, Yon, 2012).

El problema debe matizarse sensiblemente dependiendo de las "minorías" de que se trate. Algunas poseen un estatus social más o menos transitorio: los jóvenes, los inmigrantes, los "seniors". Las mujeres, en cambio, no constituyen una "minoría" en sentido numérico. Si la dominación histórica de los hombres en el seno del sindicalismo se encuentra íntimamente relacionada con la concepción de la estabilidad salarial y de los derechos sociales que le están asociados (¿no constituye la sobreexposición de las mujeres a la precariedad profesional un legado de su posición subordinada, tanto en la sociedad como en el movimiento sindical?), la reestructuración del sindicalismo a favor del precariado supone que se lleve a cabo, en la práctica, una revolución...feminista.

Por lo que respecta a las "demás" "minorías", cabe recordar ante todo cuán imbricadas se encuentran las distintas modalidades de inferiorización social con los procesos de debilitamiento profesional. Son numerosas las mujeres de origen inmigrante que se hallan ocupadas en empleos de servicio poco calificados. Asimismo, son numerosos en la restauración los y las jóvenes de origen inmigrante. La combinación de modos de opresión múltiples también puede invertirse para dar lugar a combinaciones de las modalidades de la emancipación, pudiendo el antirracismo y/o la emancipación femenina alimentar la lucha salarial. Tal es el caso de ciertos "jeunes des cités" -término que designa a los jóvenes procedentes de las inmigraciones africanas que crecieron en los barrios de vivienda social situados en la peri- 
feria de las grandes ciudades- que se incorporan al sindicalismo: cuando logran ser contratados en la industria automovilística, se rebelan contra la jerarquía fabril, como prolongación de una "cultura callejera" forjada a través de la confrontación con las fuerzas del orden (Berthonneau, 2011).

Los asalariados inmigrantes o de origen inmigrante han suministrado siempre importantes contingentes de mano de obra precaria. La reciente lucha de los trabajadores indocumentados en Francia demuestra que la precariedad no condena ni al silencio ni a la invisibilidad (Barnier y Perrin, 2009; Barron et al., 2011). Este movimiento no deja de recordar la acción que llevaron a cabo los work centers con los jornaleros mexicanos indocumentados de Chicago (Chauvin, 2009; 2010). Tanto en Estados Unidos como en Francia, las políticas de inmigración se llevan a cabo en medio de serias contradicciones, entre el cierre de fronteras y la movilización de hecho de sectores enteros de actividad en los que trabaja una mano de obra que carece por completo de derechos civiles. En ambos casos la hipocresía de los empleadores se enfrenta a la fuerza de las solidaridades comunitarias, la inventiva militante y la valentía de los (las) interesados(as). Con una diferencia notable que separa las tradiciones y culturas de lucha: en los Estados Unidos, el papel de los movimientos de consumidores; en Francia el de un sindicato como la CGT, adepto a la acción arraigada en el lugar de trabajo.

En el caso de los jóvenes, parece imposible separar esta característica, transitoria, de sus demás características sociales, las cuales determinan en amplia medida sus destinos sociales. Es mayor la probabilidad de que se estabilicen y escapen progresivamente de los empleos de menor rango si son hombres, poseen un nivel mínimo de estudios y no proceden de la inmigración. Tal es el perfil de los jóvenes empleados de correos, todos ellos ex trabajadores precarios, quienes encabezaron una huelga en la distribución de paquetes, la cual mezclaba íntimamente reivindicaciones relacionadas con el modo de mando, el trabajo y el empleo (Bouffartigue, 2009). Para los jóvenes con un perfil social distinto, resulta más problemático el desfase entre sus estilos culturales y los que siguen prevaleciendo en el sindicalismo. Semejante estado de cosas quizá pueda modificarse gracias a la multiplicación y el reconocimiento, dentro del sindicalismo, de "trayectorias militantes" procedentes de experiencias positivas del aprendizaje militante, en particular a través de las huelgas (Collovald y Mathieu, 2009).

Sin embargo, la actual debilidad del movimiento sindical no se debe solamente a su incapacidad para alcanzar y organizar a las fracciones más vulnerables de los trabajadores asalariados, sino también para representarlas dando a conocer su existencia a través del discurso y la movilización. Resulta también de sus dificultades para reestructurarse dentro de espacios productivos ampliamente modificados. De lo que se trata, no es de llevar a cabo una simple mutación organizativa, similar a la que se realizó a principios del siglo XX con el paso de un sindicalismo gremial a un sindicalismo industrial. Es al mismo tiempo la estructuración organizativa de las confederaciones en su conjunto la que necesita reconfigurase, no sólo a nivel de sus prácticas de representación, sino también de su movilización interna. Los desfases con respecto a las dinámicas de evolución de los trabajadores asalariados imponen 
tanto une redefinición de los campos federales, como una reestructuración de la acción interprofesional, con el doble reto de tomar en cuenta la organización administrativa y política del Estado (departamento, región) y la del capital. ${ }^{4}$ Sin embargo, estos cambios serán aún más significativos $-\mathrm{y}$ al mismo tiempo aparecerán menos como simples maniobras dirigidas desde arriba- si se inscriben dentro de un proyecto sindical susceptible no sólo de convertir a los asalariados precarios en sujetos de un proceso de afirmación política, sino también de unificar sus experiencias.

Hoy por hoy existen varios intentos, en particular dentro de la CGT, por desarrollar una concepción distinta de la relación con el territorio y crear sindicatos territoriales que permitan hacer frente a la atomización de las empresas y a la práctica de la subcontratación. Tal es el caso, en particular, en varios grandes centros comerciales donde los sindicatos están implantados en las tiendas de grandes marcas, y no en los comercios independientes o que operan bajo el régimen de la franquicia. En tales condiciones, la creación de un sindicato de local apunta a desplegar una acción transversal, en particular en materia de seguridad laboral, más allá de los estatus de empleo y el tipo de empleadores (Béroud, 2009). No obstante, si bien estos experimentos son valorados dentro de la organización, tienden a agotarse rápidamente, debido a que las fuerzas militantes que se dedican a ellos son poco numerosas y permanecen confinadas dentro de posiciones relativamente periféricas. Pero sobre todo se enfrentan a distintas formas de inmovilismo, ya sea con el fin de preservar poderes establecidos o de mantener equilibrios internos, tanto profesionales como políticos.

A este respecto llama la atención el contraste entre el esfuerzo organizativo y financiero que una parte de los sindicatos norteamericanos dedican a su "revitalización", y los escasos recursos con los que cuentan los equipos sindicales, e incluso a veces un reducido número de militantes, para tratar de (re)anudar lazos con los asalariados en situación precaria y hacer surgir un potencial de acción colectiva. Mientras que el debate en torno a las estrategias de renovación de las formas organizativas (union renewal) y de sindicalización de categorías de asalariados poco organizadas (union revitalization) se encuentra muy presente en el sindicalismo del mundo anglosajón (Scandella, 2009), al parecer no ha tenido impacto directo en Francia. Es cierto que es de actualidad la cuestión de la reestructuración de los ámbitos "federales", es decir, de la reorganización del campo de acción de las federaciones profesionales y de la creación de federaciones "multisectoriales" (Thomas, 2008). Sin embargo, otros elementos clave presentes en el debate anglosajón sobre la revitalización -sin pretender con ello prestar a este debate alguna virtud "mágica" - sólo emergen en forma marginal dentro del sindicalismo francés: como son la conexión con los movimientos sociales de fuera de la empresa, la

${ }^{4}$ A este respecto cabe recordar la célebre fórmula de Léon Jouhaux ("quiero un prefecto de la CGT en todos los departamentos") que ratificó la supremacía de los Uniones Departamentales sobre las Bolsas de trabajo. 
puesta en marcha de prácticas de movilización, los dispositivos concretos de extensión del sindicalismo hacia sectores de actividad o categorías de trabajadores asalariados donde éste no se encuentra presente (Turner et al., 2001).

Entre otros motivos, esta situación obedece probablemente a la concepción que impera dentro de las direcciones confederales en torno a la legitimidad del sindicalismo -es decir, principalmente su inscripción en el campo de las relaciones profesionales y su estatus de interlocutor reconocido por el Estado- y a las posibilidades de sindicalización, mediante una relación individualizada con cada asalariado considerado ante todo como un elector. Además, es sorprendente constatar hasta qué grado esta limitación contemporánea del sindicalismo al ámbito de las relaciones profesionales resulta de historias organizativas y políticas distintas.

Es, por lo tanto, un modelo de sindicalismo el que está en juego. La idea de que el movimiento sindical pueda inscribirse, al lado de otros movimientos sociales, dentro de una dinámica de re-movilización de los trabajadores asalariados, en particular de los proletarios del mundo moderno, entra parcialmente en contradicción con intereses institucionales, a la vez más inmediatos y mejor delimitados. Sin embargo, sería reductor pensar que la opción por determinado tipo de sindicalismo corresponde de manera clara a tal o cual sigla sindical, ya que estas tensiones permean el funcionamiento interno de las organizaciones en distintos niveles.

Desde este punto de vista, una de las originalidades recientes del sindicalismo francés o, por lo menos, de una parte de sus componentes (la CGT, Solidaires, la Féderation Syndicale Unitaire - FSU -, ciertas estructuras de "oposición" dentro de la CFDT - Conféderation Française Démocratique du Travail -) consiste en haber acompañado el surgimiento de un movimiento de desempleados y haber participado -ya sea mediante la organización directa de comités de desempleados o la participación militante dentro de $\mathrm{AC} !^{5}$ - en debates sobre la relación con el trabajo y el empleo, sobre la imposición de formas de empleo degradadas y sobre las maneras de concebir a los trabajadores asalariados (Cohen, 2008). Asimismo, otros movimientos sindicales - piénsese en el caso de Bélgica, por ejemplo- han tenido que hacer frente a las reivindicaciones formuladas por los comités de desempleados, reivindicaciones no sólo en términos de lugar y reconocimiento en las estructuras sindicales, sino también de derechos a un ingreso mínimo. La influencia que estos movimientos han ejercido sobre los marcos conceptuales, sobre la evolución de los debates militantes, merecería estudiarse por su importante contribución al desplazamiento de las reivindicaciones, a su reformulación (sobre los servicios públicos, sobre el acceso a los ingresos, sobre los derechos sociales inalienables, etc.). No obstante, a pesar de que estos movimientos planteen claramente la necesidad de que el sindicalismo se haga cargo de las fracciones de los trabajadores asalariados excluidos del empleo o de que permanezcan de manera intermitente al margen de éste, han sido concebidos a veces exclusivamente desde la óptica de la competencia

\footnotetext{
${ }^{5} \mathrm{AC}$ !: Red de lucha contra el desempleo, la precariedad y las exclusiones [N. del T.].
} 
entre asociaciones y sindicatos, e incluso en términos de "minorías" algo embarazosas y excesivamente politizadas si se piensa en las tensiones que pudieron existir entre el comité nacional de desempleados CGT y la confederación a principios de los años 2000 (Béroud, 2013). Sin embargo, fue a partir de los movimientos de desempleados cuando surgieron iniciativas concretas de ampliación hacia los "precarios" y de construcción de colectivos transversales, ya sea sobre temas reivindicativos (tales como el derecho a la energía o a la vivienda), o bien partiendo de la necesidad de actuar fuera de la empresa, en el plano de los barrios residenciales.

Este ejemplo permite ilustrar el hecho de que el sindicalismo se encuentra en movimiento, de una manera a la vez parcial y diversa. Ya sea que surjan dentro de una unión local o-lo que es menos frecuente- dentro de un sindicato de empresa, o que sean impulsadas por militantes sensibilizados sobre el tema de la precariedad debido a su trayectoria biográfica o comprometidos con estructuras "atípicas" tales como los comités de desempleados, estas iniciativas suelen presentar características comunes, como son su fragilidad y su carácter minoritario dentro de la organización. Sus limitaciones se deben en parte a la falta de medios suficientes, tanto militantes como logísticos: una carencia relacionada no solamente con el hecho de que el sindicato se encuentra a veces en vías de construcción (piénsese en los sindicatos de la Unión Sindical Solidaires), sino también con el hecho de que suele estar en posición de debilidad ante la subcontratación, ante el juego de poderes y responsabilidades entre empleadores múltiples, ante las formas que adopta la represión sindical, etc. Por lo tanto, lo que al parecer hace falta actualmente en el movimiento sindical francés -contrariamente a lo que dejan entrever las estrategias de reestructuración, tal como son concebidas dentro de otros sindicalismos- es ante todo la voluntad de concebir el reto de la precarización en términos globales y de dotarse de los medios necesarios para un acercamiento reflexivo a las dificultades encontradas y los experimentos en curso.

Controlar tanto la movilidad profesional como el proceso laboral: estas dos finalidades antiguas del movimiento sindical y obrero se plantean en un contexto profundamente renovado, el de la tendencia a una fuerte re-mercantilización del trabajo. Podemos preguntarnos si el sindicalismo no se ha encerrado él mismo, por lo menos en parte, en el horizonte de las formas de estabilización que ha logrado conquistar, principalmente la estabilización de la relación de empleo. De ahí la magnitud de los desafíos que consisten en reinventar perspectivas de seguridad que tengan sentido y abran perspectivas, no sólo para su base social actual, en vías de contracción, sino también para un precariado en vías de expansión.

\section{Bibliografía}

Traducción de: Jean Hennequin

Barnier, L.M. y Perrin, E. (2009). "Des 'papiers pour tous' à la régularisation par le travail. La grève d'avril 2008 et la CGT", en S. Béroud y P. Bouffartigue (dirs.), Quand le travail se précarise, quelles résistances collectives? La Dispute, pp. 289-304. 
Barron, P., Bory, A., Chauvin, S., Jounin, N., Tourette, L. (2011). On bosse ici, on reste ici! La grève des sans papiers, une aventure inédite, La Découverte.

Beau, A.S. (2009). "La gestion de la main d'œuvre dans le grand commerce: un usage continu de la précarité (XIXe-XXe)", en S. Béroud y P. Bouffartigue (dirs.), Quand le travail se précarise, quelles résistances collectives? La Dispute, pp. 45-58.

Benquet, M. (2011). Les damnées de la caisse. Enquête sur une grève dans un hypermarché, Editions du Croquant.

Béroud, S. (2013). "L'influence contrariée des 'privés d'emploi' dans la CGT”, en D. Chabanet, J. Faniel (dirs.), Les mobilisations de chômeurs en France. Problématiques d'alliances et alliances problématiques, Paris, L'Harmattan, pp. 153-176.

Béroud, S., Le Crom, J-P., Yon, K., (2012). "Représentativités syndicales, représentativités patronales. Règles juridiques et pratiques sociales", Travail et Emploi, $\mathrm{n}^{\circ} 131$, juillet-septembre 2012, pp. 5-22.

Béroud, S., (2009). "Organiser les inorganisés: des expérimentations syndicales entre renouveau des pratiques et échec de la syndicalisation", Politix, $\mathrm{n}^{\circ} 85$, vol. 22, pp. 127-146.

Berthonneau, C. (2011). Se syndiquer au-delà de la classe ouvrière. Les formes de reproduction du militantisme ouvrier dans la sous-traitance automobile, memoria de maestría, ENS-EHESS.

Bouffartigue, P. (2009). "Attendre le CDI pour faire grève et se syndiquer? Précaires et action collective à la Poste", en S. Béroud y P. Bouffartigue (dirs.), Quand le travail se précarise, quelles résistances collectives? La Dispute, pp. 133-147.

Bourguignat, N. (1993). "Le développement de l'électrométallurgie en Maurienne: recomposition et nouvelles régulations d'un milieu rural en crise (1897-1921)", Le Mouvement social, $\mathrm{n}^{\circ}$ 165, pp. 43-65.

Chauvin, S. (2009). "Des mobilisations bridées. Vertus et limites du syndicalisme informel parmi les travailleurs journaliers aux Etats-Unis", en S. Béroud y P. Bouffartigue (dirs.), Quand le travail se précarise, quelles résistances collectives? La Dispute, pp. 253-270.

Chauvin, S. (2010). Les agences de la précarité. Journaliers à Chicago, Seuil.

Cingolani, P. (2009). "Ce qu'il y a de nouveau dans le travail précaire. Ouvrir la réflexion savante sur le questionnement politique", en S. Béroud y P. Bouffartigue 
(dirs.), Quand le travail se précarise, quelles résistances collectives? La Dispute, pp. 59-75.

Cohen, V. (2008). "Transformations et devenir des mobilisations collectives de chômeurs", Les Mondes du travail, n6, pp. 91-102.

Collovald, A. y Mathieu, L. (2009). "La pédagogie morale de la grève", en S. Béroud y P. Bouffartigue (dirs.), Quand le travail se précarise, quelles résistances collectives? La Dispute, pp. 191-204.

Cottereau, A. (2002). "Droit et bon droit. Un droit ouvrier instauré, puis évincé par le droit du travail (France XIXème siècle)", Annales. Histoire, Sciences Sociales, $\mathrm{n}^{\circ} 2$, pp. 1521-1557.

Denis, J.-M. (2009). “ 'Dans le nettoyage, c'est le chantier qui part en grève !', Obstacles et recours à la lutte dans le secteur du nettoyage industriel", en S. Béroud y P. Bouffartigue (dirs.) Quand le travail se précarise, quelles résistances collectives? La Dispute, pp. 99-116.

Dufour, C. Hege, A. (2009). "Les syndicats face au processus d'insécurisation des statuts d'emplois", en S. Béroud y P. Bouffartigue (dirs.) Quand le travail se précarise, quelles résistances collectives? La Dispute, pp. 77-89.

Ferreras, I. (2007). Critique politique du travail: travailler à l'heure de la société des services, Paris, Presses de Sciences-Po.

Germe, J.-F. (1981). "Instabilité, précarité, et transformations de l'emploi", Critiques de l'Economie Politique, n 15/16, pp. 53-91.

Miguélez F. y Prieto C. (2008), «L'autre côté de la croissance de l'emploi: une précarité qui se perpétue », Travail et Emploi, $\mathrm{N}^{\mathrm{o}} 115$, junio-septiembre 2008, pp. 45-58

Pennef, J. (1993). "Le recrutement et l'observation des ouvriers par le patronat. Etude d'un fichier d'entreprise", Revue française de sociologie, 34-4, pp. 557-596.

Pernot, J-M., Pignoni M-T. (2008). "Les salariés et les organisations syndicales de 1992 à 2004: une longue saison de désamour", en T. Amossé, C. Bloch-London, L. Wolff (dirs.), Les relations sociales en entreprise, Paris, La Découverte, pp. 140-162.

Perrin, E. y Peroumal, F. (2009). "Ça ne se passera plus comme ça chez McDonald's, retour sur un conflit dans la restauration rapide", en S. Béroud y P. Bouffartigue (dirs.), Quand le travail se précarise, quelles résistances collectives? La Dispute, pp. 223-236. 
Pigenet, M. (2009). "Bûcherons, dockers: des expériences syndicales au cœur du salariat précaire (fin XIXe - début XXIe siècles)", en S. Béroud y P. Bouffartigue (dirs.), Quand le travail se précarise, quelles résistances collectives? La Dispute, pp. 29-44.

Ramaux, C. (2006). Emploi: éloge de la stabilité, Mille et Une Nuits.

Retière, J.-N. (1995). "L'industrie des tabacs dans la deuxième moitié du XIXème siècle, un patronage d'Etat", en M. Mansfield, R. Salais, N. Whiteside (dirs.), Aux sources du chômage 1880-1914, Paris, Belin, pp.111-139.

Sauze, D. (2005), "Stabilité de l'emploi: conquête sociale ou politiques patronales?", Travail et Emploi, $\mathrm{n}^{\circ} 103$, pp. 113-122.

Scandella, F. (2009). "Renouveau syndical dans le secteur du nettoyage. La campagne londonienne 'Justice for cleaners' ", en S. Béroud y P. Bouffartigue (dirs.), Quand le travail se précarise, quelles résistances collectives? La Dispute, pp. 117131.

Standing G. (2011), The precariat. The new dangerous class, Londres, Bloomsbury Academic.

Thomas, A. (2008). Entre démocratie militante et efficience managériale. Rationalisation syndicale et création de fédérations multibranches en France et en Allemagne, tesis de doctorado de ciencia política, Université Paris 1 (dir.: Michel Offerlé).

Trentin, B. (2012). La cité du travail. Le fordisme et la gauche, Fayard, Coll. "Poids et mesures du monde".

Turner L., Katz H. C., Hurd R. W. (eds.) (2001). Rekindling the movement. Labor's quest for relevance in the 21st century, New York, Cornell University Press.

Vatin, F. y Pillon, T. (2007). "La question salariale: actualité d'un vieux problème", F. Vatin, S. Bernard (col.), Le salariat. Théorie, histoire et formes, La Dispute.

Vigna, X. (2007). L'insubordination ouvrière dans les années 1968. Essai d'histoire politique des usines. Rennes, Presses universitaires de Rennes, 2007. 